\title{
Comparison of Patient Satisfaction and Complications of Rhinoplasty between Local and General Anesthesia
}

\author{
Sung Jae Heo ${ }^{1}$, Eun Joo Cha ${ }^{1}$, Hyun Soo Cho ${ }^{1}$, Ji Hye Park ${ }^{1}$, Jin Geol Lee ${ }^{2}$, and Jung Soo Kim ${ }^{1}$ \\ ${ }^{I}$ Department of Otorhinolaryngology-Head and Neck Surgery, Kyungpook National University School of Medicine, Daegu; and \\ ${ }^{2}$ Department of Otorhinolaryngology-Head and Neck Surgery, Daegu Fatima Hospital, Daegu, Korea
}

국소마취와 전신마취로 시행된 비성형술의 환자 만족도과 합병증 비교

허성재 ${ }^{1} \cdot$ 차은주 $^{1} \cdot$ 조현수 ${ }^{1} \cdot$ 박지혜 $^{1} \cdot$ 이진걸 $^{2} \cdot$ 김정수 $^{1}$

경북대학교 의과대학 이비인후-두경부외과학교실, ${ }^{1}$ 대구파티마병원 이비인후과 ${ }^{2}$

Received June 22, 2017

Revised September 11, 2017

Accepted September 12, 2017

Address for correspondence

Jung Soo Kim, MD

Department of Otorhinolaryngology-

Head and Neck Surgery,

Kyungpook National University

School of Medicine,

130 Dongdeok-ro, Jung-gu,

Daegu 41944, Korea

Tel $+82-53-420-5777$

Fax $+82-53-423-4524$

E-mail profsookim@gmail.com
Background and Objectives Since rhinoplasty techniques require meticulous and delicate manipulation, proper anesthesia is essential. The aim of the current study is to compare patient satisfaction and complication of rhinoplasty performed under local anesthesia against general anesthesia.

Subjects and Method Patients who underwent rhinoplasty by a single surgeon between March 2014 and January 2017 were enrolled in this study. Midazolam was utilized to sedate the patient during local anesthesia. Pain and memory of surgery under local anesthesia, satisfaction of anesthesia, and willingness to undergo the surgery with the same anesthesia method again were evaluated. Cardiopulmonary events, nausea, and vomiting were assessed as complications. Aesthetic satisfaction of patients and the doctor was evaluated 6 month after the surgery. The parameters were compared between local and general anesthesia.

Results A total 120 patients were included in this study. The degree of pain was low during surgery under local anesthesia. Although most of patients remembered the process of surgery during local anesthesia, satisfaction of local anesthesia was high. The satisfaction of anesthesia and willingness to undergo surgery with same anesthesia were not signifcantly different between local and general anesthesia. No serious complications developed during local anesthesia and there were no signifcant differences of aesthetic satisfaction between local and general anesthesia.

Conclusion Patient satisfaction and aesthetic results of rhinoplasty performed under local anesthesia were comparable to general anesthesia, indicating that surgeons do not need to be afraid of applying local anesthesia in rhinoplasty.

Korean J Otorhinolaryngol-Head Neck Surg 2018;61(5):247-51

Key Words General anesthesia · Local anesthesia · Patient satisfaction · Rhinoplasty.
서 론

비성형술은 섬세한 조작이 필요하므로 환자의 움직임이 없는 안정적인 수술 환경이 필요하다. 따라서 비성형술에서

This is an Open Access article distributed under the terms of the Creative Commons Attribution Non-Commercial License (http://creativecommons.org/licenses/by-nc/4.0) which permits unrestricted non-commercial use, distribution, and reproduction in any medium, provided the original work is properly cited.
적절한 마취는 매우 중요하다. 일반적으로 환자의 성격이 예 민하거나 통증에 민감한 경우, 수술 시간이 긴 경우, 절골술 과 같은 침습적인 술기를 하는 경우에는 전신마취를 선택하 고, 심폐질환과 같은 기저질환이 많은 경우나 환자가 전신마 취에 대한 거부감이 있는 경우에는 국소마취를 선택한다.

국소마취를 시행하면 마취 비용을 줄일 수 있고 회복이 빠 르며 수술 후 심폐 합병증이 낮은 등의 장점이 있고, 전신마취 
를 시행하면 수술 중 환자의 움직임이나 통증에 대해 걱정할 필요가 없고 혈압이나 산소포화도와 같은 활력 징후를 마취 과 의사가 조절하므로 집도의는 수술에 좀 더 집중할 수 있 다. 지금까지 코성형술을 받은 환자에서 마취 종류에 따른 만족도와 합병증에 대한 연구가 없었다. 이에 저자들은 국소 마취 및 전신마취로 시행된 코성형술에서 환자의 만족도와 합병증을 비교 분석하고자 하였다.

\section{대상 및 방법}

2014년 3월부터 2017년 1월까지 경북대학교병원 이비인후 과에서 단일 술자에게 비성형술을 받은 환자들을 대상으로 하였고, 이전에 코수술을 받은 경험이 있거나 비중격 및 하비 갑개를 제외한 다른 수술을 같이 시행한 경우, 환자가 본 연구 에 동의하지 않은 경우는 연구에서 제외하였다. 연구는 경북 대학교병원의 임상연구심의위원회의 승인을 받은 후 전향적으 로 진행되었다(Institutional Review Board No. KNUH201309-015).

전신마취와 국소마취 중 마취방법의 선택은 두 마취방법 의 장단점을 설명한 후 환자의 선호에 따라서 선택되었다. 환 자가 전신마취를 선택한 경우 마취과 의사가 판단했을 때 전 신마취를 시행하기에 위험이 있는 경우에는 국소마취로 진행 되었다. 국소마취 수술은 진정제 사용에 문제가 없는 경우 모 든 환자에서 midazolam을 사용하여 진행하였고, midazolam 투여 용량은 수술 15 분 전 근육주사로 $0.05 \mathrm{mg} / \mathrm{kg}$ 를 투여하 고, 수술 중 환자의 진정 정도가 부족하다고 판단되면 1 2 mg 을 추가로 투여하였다. 60세 이상이거나 전신 쇠약감(general weakness)이 있는 경우 초기 투여 용량을 반으로 줄였고, 추가 투여도 조심스럽게 결정하였다. 통증 조절을 위해 pethidine $50 \mathrm{mg}$ 을 증류수 $100 \mathrm{~mL}$ 에 혼합하여 주사해서 수술 초기의 통증을 조절하였고, nefopam $60 \mathrm{mg}$ 을 normal saline 500 $\mathrm{mL}$ 에 혼합하여 정맥 내 지속 주사하여 수술 중과 후의 통증 을 조절하였다. 수술 부위는 2\% lidocaine을 1:100000 epinephrine한 용액을 사용하여 마취하였다. 수술 시간은 환자 가 수술실에 입실해서 퇴실할 때까지의 시간으로 정하였다.

수술 후 설문조사(Fig. 1)로 마취의 만족도를 조사하였고, 다음에 동일한 수술을 받을 기회가 있다면 같은 마취방법을 선택할지에 대해 예/아니오 중 한 가지로 대답하게 하였다. 국 소마취의 경우 수술 중 느낀 통증의 정도와 대부분의 수술 이 기억나는지 여부를 추가로 조사하였다. 마취의 만족도와 통증의 정도는 0 10점 사이의 visual analogue scale(VAS) 점수로 평가하였고, 통증이 클수록, 마취 만족도가 높을수 록 높은 숫자를 선택하게 하였다. 국소마취 수술에서 수술

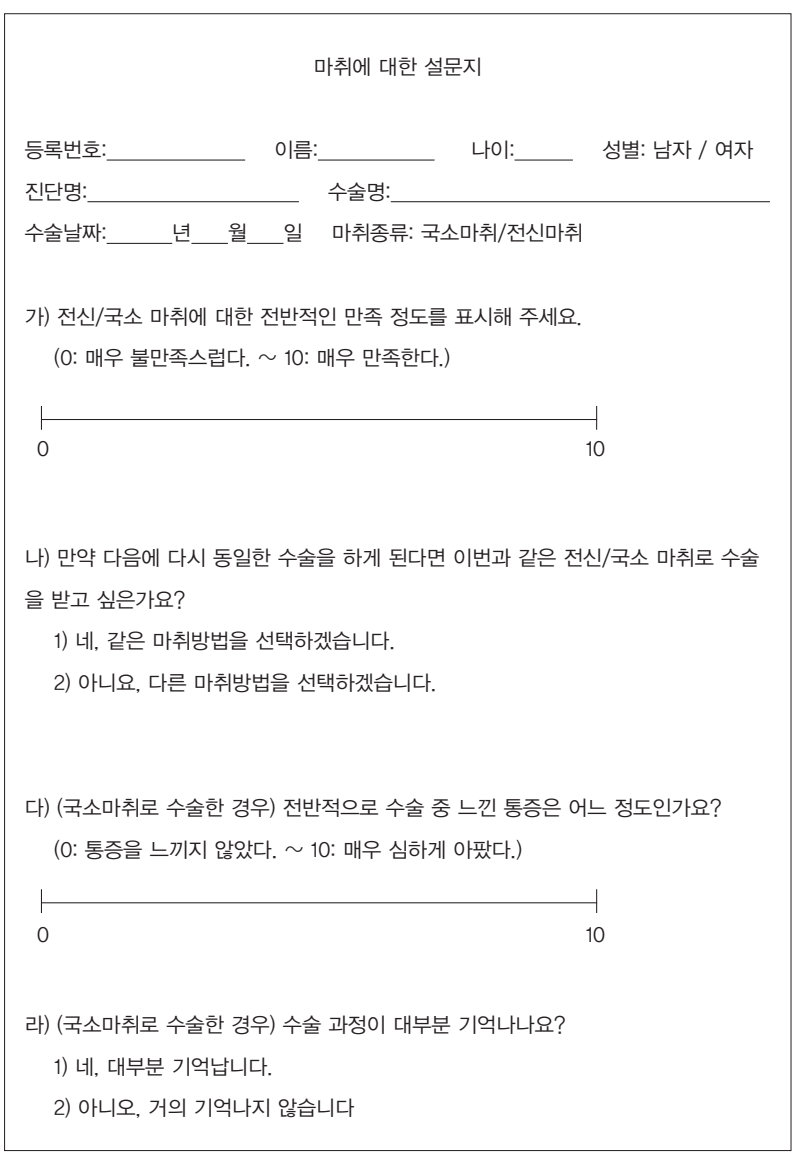

Fig. 1. Patient questionnaire about anesthesia.

중 합병증은 평균 동맥압이나 심장박동 수가 처음에 비해 $20 \%$ 이상 차이가 나는 경우, 말초 산소포화도가 $92 \%$ 이하로 낮아지는 경우, 오심이나 구토가 있는 경우, 환자나 술자에 의해 수술이 중단되는 경우로 정하였고, 활력 징후는 5 분마 다 측정하여 평가하였다. 수술 후 합병증으로는 오심 및 구토, 처치가 필요한 출혈로 정하여 평가하였다. 이러한 변수들을 국소마취와 전신마취 수술 간에 비교 분석하였다.

국소마취 및 전신마취로 수술한 모든 환자에서 수술결과 를 확인하기 위해 수술 6 개월 후 환자의 주관적인 만족도 설 문과 의사의 주관적 평가를 시행하였다. 수술결과를 매우 만 족(3점), 만족(2점), 양호(1점), 불만족(0점)의 4가지 항목 중 선 택하게 하였고, 의사의 평가는 수술에 참여하지 않은 2 명의 전문의가 평가하였다. 통계는 SPSS statistics version 18.0 (SPSS Inc., Chicago, IL, USA)을 이용하여 Fisher's exact test, independent t-test, Mann Whitney U-test를 시행하여 결과값을 비교하였고, $p$ value가 0.05 미만인 경우에 통계적 으로 유의한 것으로 판단하였다. 
Table 1. Patient characteristics at baseline $(n=120)$

\begin{tabular}{|c|c|c|c|}
\hline Variables & Local anesthesia $(n=105)$ & General anesthesia $(n=15)$ & p-value \\
\hline Male/female & $85 / 20$ & $12 / 3$ & 1.000 \\
\hline Age $(y r)$ & $31.6 \pm 13.1$ & $34.5 \pm 10.8$ & 0.474 \\
\hline Surgery type & & & 1.000 \\
\hline Rhinoplasty with septoplasty & 101 & 15 & \\
\hline Rhinoplasty without septoplasty & 4 & 0 & \\
\hline Approach type & & & 0.072 \\
\hline Open rhinoplasty & 82 & 15 & \\
\hline Closed rhinoplasty & 23 & 0 & \\
\hline Total dose of midazolam (mg) & $4.17 \pm 1.15$ & NA & NA \\
\hline $\begin{array}{l}\text { Number of times of midazolam administration } \\
\text { after initial injection }\end{array}$ & $0.78 \pm 0.66$ & NA & NA \\
\hline Duration of operation time (min) & $171.3 \pm 40.1$ & $205.1 \pm 16.1$ & $<0.001$ \\
\hline
\end{tabular}

Data are presented as number or mean with standard deviation. NA: not available

Table 2. Results of patient questionnaire about satisfaction degree of rhinoplasty under local anesthesia

\begin{tabular}{lccc}
\multicolumn{1}{c}{ Variables } & $\begin{array}{c}\text { Local anesthesia } \\
(\mathrm{n}=105)\end{array}$ & $\begin{array}{c}\text { General anesthesia } \\
(\mathrm{n}=15)\end{array}$ & $\mathrm{p}$-value \\
\hline Degree of pain during surgery (VAS, 0-10) & $3.5 \pm 1.8$ & NA & NA \\
Keep memory of most of the surgery process (yes/no) & $71 / 34$ & $7.5 \pm 1.6$ & NA \\
Degree of satisfaction of anesthesia (VAS, 0-10) & $96 / 9$ & $15 / 0$ & 0.189 \\
$\begin{array}{l}\text { Willingness to undergo the surgery with same anesthesia } \\
\text { method again (yes/no) }\end{array}$ & & 0.600 \\
\hline
\end{tabular}

Data are presented as number or mean with standard deviation. VAS: visual analogue scale, NA: not available

Table 3. Results of anesthesia related complications during rhinoplasty under local anesthesia

\begin{tabular}{lc}
\hline \multicolumn{1}{c}{ Variables } & Number \\
\hline Cardiopulomonary event & \\
Mean arterial pressure $>$ or $<20 \%$ of baseline & 31 \\
Heart rate $>$ or $<20 \%$ of baseline & 25 \\
Peripheral oxygen saturation $<92 \%$ & 7 \\
Intervention related to cardiopulmonary event & $4^{*}$ \\
Nausea/vomiting & 2 \\
Number of cessation of the surgery (by patient & 0 \\
request or due to complication) & \\
*antihypertensive drug was administered &
\end{tabular}

\section{결 과}

본 연구 기간 동안 단일 술자에게 비성형술을 받은 213명 중, 이전에 코수술을 받았었거나 비중격 및 하비갑개를 제외 한 다른 수술을 같이 시행한 32명, 연구에 동의하지 않거나 기 록이 부족한 61 명을 제외하여 총 120 명이 본 연구에 포함되 었다. 국소마취는 105 명, 전신마취는 15 명의 환자에서 시행되

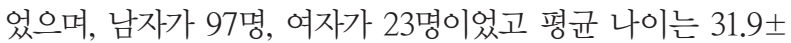
12.5 세였다. 전신마취를 시행한 환자는 모두 비외접근법을 사용하였고, 국소마취를 시행한 경우에는 비외접근법은 82
명, 비내접근법은 23 명에서 시행되었다. 국소마취에서 총 midazolam 투여량은 평균 4.17 \pm 1.15 였고, 최초 투여 후 평균 $0.78 \pm$ 0.66회 추가 투여하였다. 수술 시간은 국소마취는 평균 171.3 \pm 40.1 분이었고, 전신마취는 $205.1 \pm 16.1$ 분으로 유의한 차이를 보였다(Table 1).

국소마취를 시행한 환자에서 수술 중 느낀 통증은 VAS 10 점 중 $3.5 \pm 1.8$ 점이었고, 105 명 중 71 명의 환자가 수술의 대 부분 과정이 기억난다고 대답하였다. 국소마취 수술에 대한 만족도는 7.5 \pm 1.6 점이었고, 전신마취 수술에 대한 만족도는 $8.1 \pm 0.7$ 점으로 유의한 차이는 보이지 않았다 $(p=0.189)$. 국소 마취로 수술받은 환자 중 96명의 환자가 다음에도 같은 수술 을 받을 경우 동일한 방법의 마취를 선택하겠다고 답했고, 전 신마취를 시행한 환자는 모두 다음에도 같은 마취 방법을 선 택하겠다고 답했다(Table 2).

국소마취 수술 중 평균 동맥압이 처음에 비해 $20 \%$ 이상 차 이가 발생한 환자 수는 31명이었고, 심장박동 수가 $20 \%$ 이상 의 차이가 발생한 환자 수는 25 명이었다. 수술 중 산소포화 도가 $92 \%$ 이하로 낮아진 경우는 7 명에서 발생하였지만, 산 소 투여와 같은 처치가 필요한 경우는 없었다. 2 명의 환자에 서 수술 중에 오심을 호소해서 항구토제를 투여하였고, 4명 의 환자에게 혈압 강하제를 투여했지만 합병증으로 인해서 
또는 환자의 요구에 의해 수술이 중단된 경우는 없었다(Table 3). 수술 후 합병증으로 오심 및 구토는 국소마취에서는 17 명(16.2\%), 전신마취는 13명(86.7\%)에서 발생하여 통계적으 로 유의한 차이를 보였다 $(p<0.001)$. 수술 후 출혈은 국소마 취에서 6 명 $(5.7 \%)$, 전신마취에서 1 명(6.7\%) 발생하여 유의한 차이는 보이지 않았다 $(p=1.000)$.

수술 후 환자의 만족도는 국소마취는 $1.78 \pm 0.77$ 점, 전신마 취는 $1.73 \pm 0.70$ 점으로 유의한 차이는 보이지 않았다 $(p=0.741)$. 의사의 만족도 또한 국소마취는 $2.14 \pm 0.69$ 점, 전신마취는 $2.20 \pm 0.56$ 점으로 유의한 차이를 보이지 않았다 $(p=0.823)$.

\section{고 찰}

전신마취는 국소마취에 비해 수술 시간이 더 길었는데, 이 는 마취 유도, 기관 내 삽관 및 발관 과정에서 시간이 추가적 으로 소요되었기 때문으로 보인다. 수술 시간이 긴 국소마취 수술에서는 환자의 불안감을 줄이고, 불쾌할 수 있는 수술 과정의 기억을 없애고, 장시간 자세 유지에 대한 불편함을 줄 이는 등의 목적으로 흔히 진정제를 투여한다. 가장 흔히 사 용하는 진정제는 propofol과 midazolam으로 propofol은 짧 은 반감기를 가져서 문제가 발생하더라도 약을 중단하면 빠 른 회복이 가능한 장점이 있다.1) 또한 약제를 일정한 속도와 용량으로 주입하는 지속정맥주입법으로 투여하므로 진정 깊 이의 변화가 적다. 하지만 고농도로 투여했을 때 25 30\%에 서 무호흡을 유발할 수 있으며 심하면 30초 이상 계속될 수 있고, 이산화탄소 증가나 저산소증에 대한 반응이 둔화될 수 있다. ${ }^{2,3)}$ Midazolam은 벤조다이아제핀계 진정-수면제로서 주로 정맥이나 근육으로 일시 주사(bolus injection)하기 때문 에 투여하기는 간편하지만, 시간에 따라서 진정 정도가 일정 하지 않을 수 있다. 반감기는 propofol보다 길지만 길항제인 flumazenil를 사용해 진정으로부터 회복시킬 수 있어서 비 교적 안전하게 사용할 수 있고, propofol에 비해 항불안 효 과가 있고 기억상실 효과가 좀 더 크다. 두 약제 모두 장단점 이 있고 진정-수면 효과도 비슷하며 어느 약물이 우월한지 증명된 바 없어서 술자의 선호도에 따라 진정제를 선택한 다. ${ }^{3,4}$ 저자들은 항불안 및 기억상실 효과가 있고, 마취과 의 사의 도움 없이 수술을 진행하기에 투여가 간편하고 길항제가 있는 midazolam을 더 선호하여 본 연구에 포함된 모든 수술 은 midazolam을 진정제로 사용하였다.

국소마취 수술에서 환자들이 수술 중 느낀 통증은 평균 VAS 3.5점으로 크지 않았고, 만족도는 VAS 7.5점으로 저자 들이 예상한 것보다 좋은 결과를 나타내었다. 기억상실 효과 가 있는 midazolam을 사용했기 때문에 환자의 대부분이 수
술 과정 기억이 없을 것으로 예상했지만, $67.6 \%$ 의 환자가 수 술 과정의 대부분을 기억한다고 대답하였다. 그럼에도 불구 하고 국소마취 수술에 대한 환자의 만족도가 높게 나타났다. 전신마취를 시행한 경우 국소마취보다 만족도가 좀 더 높게 나타났지만, 유의한 차이는 보이지 않았다. 전신마취 후 발생 할 수 있는 오심과 두통, 인후통, 배뇨 장애 등의 불편함이 결 과에 영향을 주었을 것으로 생각된다. 다시 수술을 받게 될 경우 동일한 마취를 선택하겠다고 대답한 비율이 전신마취 에서 더 높았지만 통계적으로 유의한 차이는 보이지 않았다.

국소마취 수술 중 각각 $29.5 \%$ 와 $23.8 \%$ 의 환자에서 평균 동맥압과 심장박동 수가 처음 수치보다 $20 \%$ 이상 높거나 낮 아졌다. 다소 많은 환자에서 활력 징후 이상 소견이 나타났지 만 이는 대부분 수술을 시작할 때 지혈 목적으로 국소마취 제와 함께 투여한 epinephrine의 효과로 생각되며, 국소마취 초기와 수술 중간에 통증을 호소해서 epinephrine이 포함된 국소마취제를 추가 투여했을 때 주로 나타났다. 기저질환으로 고혈압이 있던 4명의 환자를 제외하면, 혈압 상승은 모두 일 시적으로 나타났고 특별한 처치가 필요하지 않았다. 산소포화 도가 $92 \%$ 이하로 낮아진 경우는 $6.7 \%$ 에서 발생하였고, 모든 환자에서 산소 투여나 기도 삽관과 같은 처치는 필요하지 않 았으며 환자의 이름을 부르거나 몸을 움직여 깨움으로써 산 소포화도는 정상화되었다. 산소포화도가 낮아진 환자는 모두 체질량지수가 25 이상이며 목이 두껍고 인두가 좁은 수면무 호흡증이 발생하기 쉬운 구조를 가진 환자였으므로, 이러한 환자에서 진정제를 사용할 때에는 주의를 기울여야 한다. 수 술 중 2명에서 오심을 호소했는데 진통을 위해 투여한 pethidine과 nefopam에 의한 부작용으로 생각되어 진통 약물 투 여를 중단하고 항구토제를 투여한 후 증상은 모두 호전되었 다. 모든 수술에서 유의할 만한 합병증은 발생하지 않았다.

비골 골절수술에서는 전신마취를 시행한 경우 미용적인 부 분에서 결과가 더 좋았는데, 이는 국소마취로 수술할 때 환자 의 통증 호소로 완전히 교정하기 힘들 수 있기 때문으로 보인 다. ${ }^{5)}$ 하지만 본 연구에서는 마취방법에 따른 미용적 결과 차 이는 없었다. 이러한 결과의 차이는 본 연구에서 전신마취를 시행한 환자 수가 적어서 충분한 비교가 어렵고, 비골 골절의 경우 외상 후 발생하기 때문에 국소마취와 전신마취 수술이 시행되는 장소(응급실 및 수술실)와 상황의 차이가 있을 수 있 기 때문으로 보인다. 마취의 만족도는 비골 골절과 같이 본 연 구에서도 마취방법에 따른 차이는 보이지 않았다.

본 연구의 한계점으로 선택 오차(selection bias)가 있을 수 있다. 환자가 통증에 예민하고 수술에 불안감이 큰 경우 전신 마취를 선택하는 경향이 있기 때문에 국소마취와 전신마취를 받은 환자들 사이에 성향 차이가 있을 수 있다. 하지만 본 연 
구에서는 두 집단에서 만족도 및 결과 차이가 발생하지 않았 기 때문에 그 차이가 크지 않을 것으로 생각된다.

비성형술에서 마취의 선택은 의사의 선호도와 의료기관의 환경에 의해 크게 좌우된다. 하지만 환자가 자신이 원하는 마 취를 요구할 수 있기 때문에, 술자가 두 가지 마취방법을 모 두 사용할 수 있으면 환자의 만족도를 높일 수 있다. 국소마 취 수술에서 마취의 만족도와 미용적 결과가 전신마취와 차 이가 없었고 유의할 만한 합병증이 발생하지 않았으므로, 비 성형술을 국소마취로 시행하기에 두려움을 가질 필요가 없을 것으로 생각된다.

\section{REFERENCES}

1) Choi JW, Joo JD, In JH, Kim YS, Jeon YS, Ryu KH, et al. The comparison of sedation quality, side effects, and recovery profiles of propofol alone, propofol-fentanyl and porpofol-ketamine PCS for MAC. Korean J Anesthesiol 2006;50(4):428-33.

2) Taylor MB, Grounds RM, Mulrooney PD, Morgan M. Ventilatory effects of propofol during induction of anaesthesia. Comparison with thiopentone. Anaesthesia 1986;41(8):816-20.

3) Lee JW, Lee KY. Safe sedation in a private clinic. J Korean Med Assoc 2011;54(11):1179-88.

4) Walder B, Elia N, Henzi I, Romand JR, Tramèr MR. A lack of evidence of superiority of propofol versus midazolam for sedation in mechanically ventilated critically ill patients: a qualitative and quantitative systematic review. Anesth Analg 2001;92(4):975-83.

5) Al-Moraissi EA, Ellis E 3rd. Local versus general anesthesia for the management of nasal bone fractures: a systematic review and meta-analysis. J Oral Maxillofac Surg 2015;73(4):606-15. 